\title{
PI and Fuzzy Speed Controllers for PM Synchronous Motor Drive
}

\author{
Hanan Mikhael D. Habbi \\ Electrical engineering department \\ University of Baghdad
}

\author{
Sara T. Rashed \\ Electrical engineering department \\ University of Baghdad
}

\begin{abstract}
Permanent Magnet Synchronous Motor (PMSM) has been gradually more used in industrial application as a result of a rapid dynamic response and precise control. This paper proposed a high performance Field Oriented Control (FOC), which is a closed loop control to get better dynamic performance of the PMSM in addition to improve accuracy speed control.

Two types of controllers are used; the first controller is the Proportional-Integral (PI) and the second controller is a PIcontroller founded on Fuzzy-PI controller in terms of reducing steady state error, rising time, overshoot and smoother speed response. Space Vector Pulse Width Modulation (SVPWM) method is considered according to harmonics result and losses.
\end{abstract}

A MATLAB/SIMULINK program is arranged for simulating the whole drive systems. The simulation results prove the various dynamic operations.

\section{Keywords}

Permanent Magnet Synchronous Motor (PMSM), Space Vector Pulse width Modulation (SVPWM), Field Oriented Control (FOC), PI controller, fuzzy PI controller.

\section{INTRODUCTION}

Permanent magnet synchronous motor (PMSM) drives have been widely used in industrial applications because of their advantages over other motors, which including high efficiency, high power density, high torque to inertia ratio and compactness [1,2]. In PMSM the excitation is provided by a permanent magnet instead of a field winding [3]. The elimination of field winding, DC supply and slip-ring reduce the motor losses, maintenance and complexity [4]. With the high efficiency, small size and less rotor losses, PMSM are suitable for high performance drive systems such as CNC machines, robots, computer peripherals, medical instruments and industrial applications [5,6].

Since the Space Vector PWM is one of the most preferred techniques for PWM generation [7], which used widely in motor control fields because it has better DC bus voltage utilization, higher amplitude modulation index and lower harmonic content distortion, compared with all other conventional PWM techniques. Due to its superior performance characteristics.

Field Oriented Control (FOC) or so called Vector Control techniques are widely used in high performance $\mathrm{AC}$ drives which transforms the motor equations into a coordinate system that rotates in synchronism with the rotor flux vector so the flux and torque of an AC machine can be controlled independently, as in a DC machines term of vector control refers to the control techniques that control both the amplitude and the phase of ac excitation voltage. This technique allows fast dynamic response and smooth starting for PMSM [3].

The speed and current controllers are very important to successful implementation of field oriented (FOC) approach to keep the system working in steady state to satisfy the motor requirements [8]. These controllers implemented in various ways from Proportional-Integral (PI) to variable structure, Artificial Neural Networks (ANNs) and Fuzzy Logic (FL) [9].

The PI-controller has been widely used in the industry due to small, steady-state error and low costs. But it is not an easy task to search, the parameters of the KP and KI. Uncertain proportional-integral parameters may cause the system to be unstable and not robust; in addition, that PMSM is a control object of multiple variables and inherently nonlinear [8].

The applications of fuzzy logic theory to the engineering issues have drawn tremendous attention from researchers. A number of distinguished advantages that Fuzzy logic controller owned over the conventional controllers. FLC is not so sensitive to the variation of system structure, parameters and operation points and can be easily implemented in a large scale nonlinear system. Furthermore, the fuzzy logic controller is a technique that is easy to design and implement. Nevertheless, the determination of membership functions and control rules is an inevitable problem in a design. To achieve satisfactory membership functions and control rules, designer's experiences are necessary [10].

\section{LITERATURE SURVEY}

There are many research and papers are available in PMSM speed control:

R.Krishnan, R.(Ramu) (2010) [2] provides the Permanent magnet synchronous and Brushless DC Motor Drive. their switch characteristics and losses, rectifiers, and inverters are considered, The dynamic modeling of PM synchronous machines using dqo-axes in rotor orientation frames and also in space pharos variables are illustrated.

Guphran Gaua Ahmed (2013)[3] a mathematical model of (FOC-SVPWM) driving a PMSM is given. It presents also a relative study the presentation of PMSM when diverse loads are applied on PMSM and operate with diverse speed value with diverse controller.

Iulian M.T. BIROU, Calin C. RUSU, Sorin Gh. PAVEL and Virgil MAIER, (2014) [6]. They proposed robust vector control of a permanent magnet synchronous motor (PM-SM) using a fix point DSP based computing architecture with speed control systems are analyzed for different operating conditions.

Pewmaikan et.al. (2012) [9] an adaptive Fuzzy Logic compensator for PMSM Torque control system is proposed. 
The PMSM is a fundamental section of the automatic screw machine. It presents a torque control system with an adaptive fuzzy logic compensator for torque control and torque evaluation at the same time. The process of the study can add to the efficiency of torque control system and reduce the calibration time of the automatic screw machines.

Davendra Yadav, et.al. (2012) [11] design, and model the Fuzzy Logic Controller to control the speed of Permanent Magnet Synchronous Motor Drive System. The efficiency of the planned fuzzy logic controller is compared with that of the conservative PI \& PID controllers. The planned controller is used in order to defeat the nonlinearity problem of PMSM and also to reach faster settle response.

R.Rajendran and N.Devarajan, (2010) [12] studies the FPGA apprehension of a Pulse Width Modulator founded on Voltage Space Vectors. They present the study and consciousness of SVPWM for variable speed control of AC motor drives, employ Xilinx Spartan 3E FPGA device. By implementing this controller in an FPGA, very good presentation is reached.

\section{PMSM MODEL}

In a Permanent Magnet Synchronous Motor (PMSM) where the inductances vary as a function of the rotor angle, the two-phase (d-q) equivalent circuit model is a perfect solution to analyze the multiphase machines because of its simplicity and intuition.

$$
\begin{aligned}
& V_{q}=R_{s} I_{q}+\frac{d\left(\psi_{q}\right)}{d_{t}}+\omega_{e} \psi_{q} \\
& V_{d}=R_{s} I_{d}+\frac{d}{d t}\left(\psi_{d}\right)-\omega_{e} \psi_{q} \\
& \psi_{d}=L_{d} I_{d}+\psi_{m} \\
& \psi_{q}=L_{q} I_{q}
\end{aligned}
$$

By substitute the flux equations (3) and (4) in the voltages equations (1) and (2) the compacted form of the voltage is obtain as shown in equations(5) and (6).

$$
\begin{aligned}
& V_{q}=\left(R_{s}+L_{q} \frac{d}{d t}\right) I_{q}+\omega_{e} L_{d} I_{d}+\omega_{e} \psi_{m} \\
& V_{d}=\left(R_{s}+L_{d} \frac{d}{d t}\right) I_{d}-\omega_{e} L_{q} I_{q}
\end{aligned}
$$

For $\mathrm{p}_{-}$pole number machine, where $\omega_{e}=\frac{p}{2} \omega_{r}$, where $\omega_{e}$ is the mechanical rotor speed in $\mathrm{rad} / \mathrm{sec}$, formed electromechanically torque $T_{e}$ is resultant when the output power $\mathrm{P} 0$ is separated by the mechanical speed $\omega_{r}$ as:

$$
T_{e}=\left(\frac{3}{2}\right)\left(\frac{p}{2}\right)\left(\psi_{d} I q-\psi_{q} I_{d}\right)
$$

If the equation (3) and (4) is substituted in equation (7), the torque can also be expressed in the following way:

$$
T_{e}=\left(\frac{3}{2}\right)\left(\frac{p}{2}\right)\left(\psi_{m} I_{q}+\left(L_{d}-L_{q}\right) I_{d} I_{q}\right)
$$

It is apparent from the above equation that the product torque is composed of two distinct mechanisms. The first term corresponds to "excitation torque" happening between $I_{q}$ and the permanent magnet $\Psi_{m}$, while the second term correspond to the "reluctance torque "due to the saliency (differentiation in the d-axis and q-axis inductance).The motor used in this plan is surface mounted PMSM which means that $L_{d}=L_{q}$ due to the reluctance paths in rotor and $\mathrm{q}$ axis, and there for the "reluctance torque "is equal to zero ,so the torque term for SPMSM is [2]:

$$
T_{e}=\frac{3}{2}\left(\frac{p}{2}\right)\left(\psi_{m} I_{q}\right)
$$

The mechanical Torque equation is

$$
T_{e}=T_{L}+B \omega_{r}+J \frac{d \omega_{r}}{d t}
$$

Solving for the rotor mechanical speed from equation (9).

$$
\omega_{r}=\int\left(\frac{T_{e}-T_{L}-B \omega_{r}}{J}\right) d t
$$

\section{SIMULATION AND RESULTS 4.1 PI controller}

Case 1:

In this case the speed is constant and the loads variable. Simulation results are given at rated speed of $3000 \mathrm{rpm}$ and load torques varied from 0 up to $6.8 \mathrm{Nm}$ in step as [0-2-4$6.8]$ as shown in figure (1) 


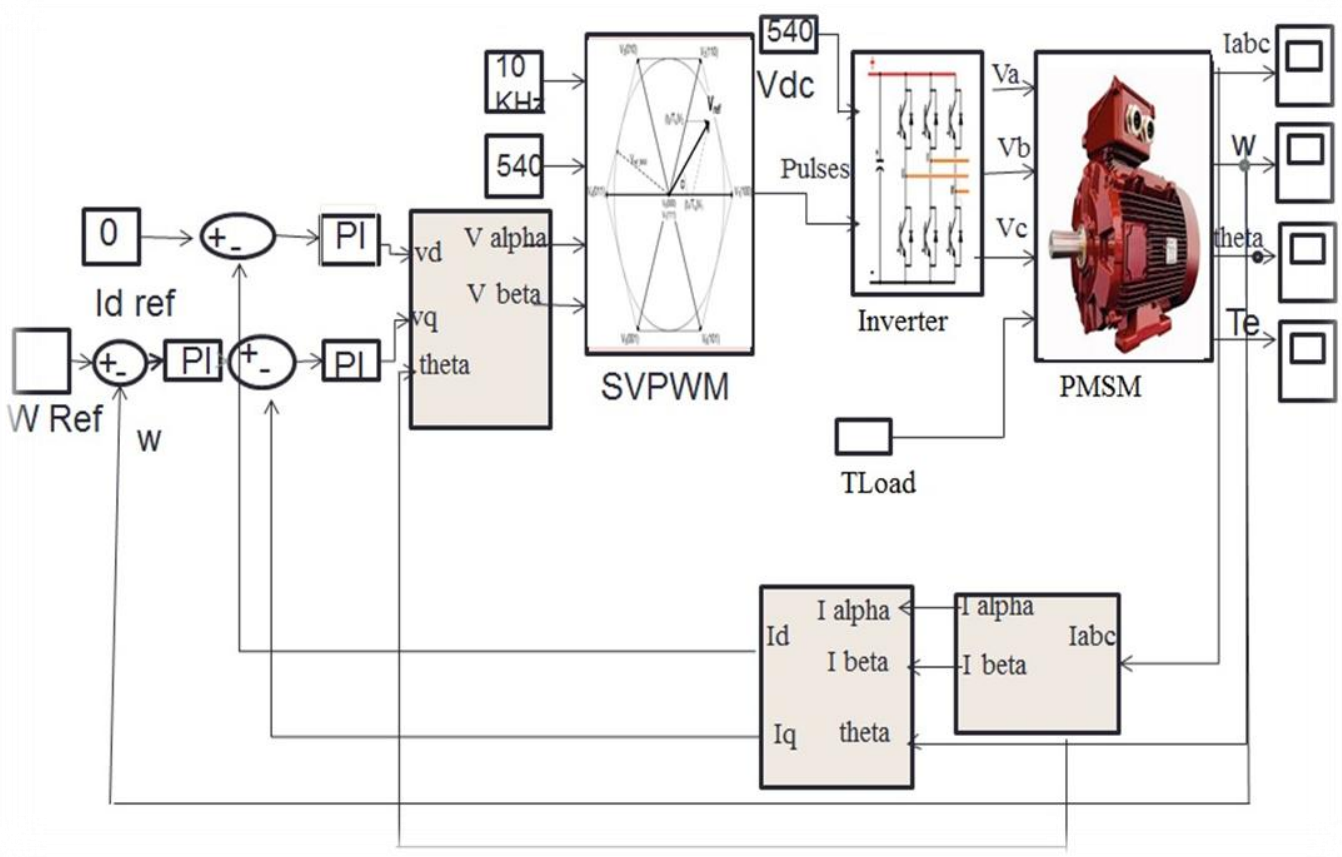

Figure (1): Simulation of PMSM

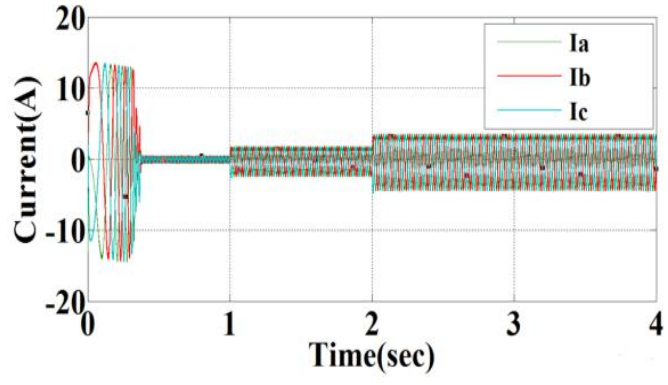

Figure (2): Iabc current response

Figure (2) shows the three phase currents, these currents are obtained using Park's reverse transformation. Until the load torque is applied the current is zero except at starting. The three phase current have a higher ripple is about $7 \%$ and the max overshoot equal to $0.01 \%$.

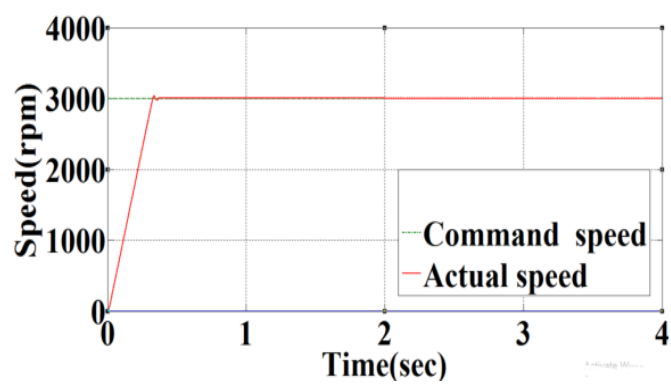

Figure (3): speed response

Figure (3) shows a variation of speed with time. The steady state speed is the same as that of the reference speed at no-load but there is a steady state error when the load is applied to the motor after $0.1 \mathrm{sec}$.

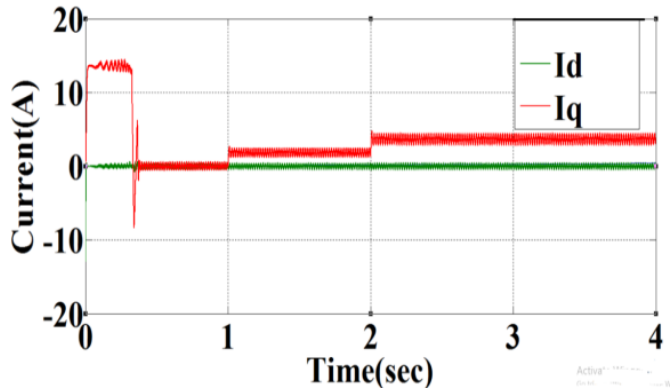

Figure (4): Iqd current response

The $\mathrm{d}$ and q component of the stator current is given in Figure (4). In the field oriented control method the value of $I_{d}$ must be zero for constant torque operation. During loading, only qaxis current increase in order to generate the necessary torque. The torque ripple $(\operatorname{Tr}=0.07)$.

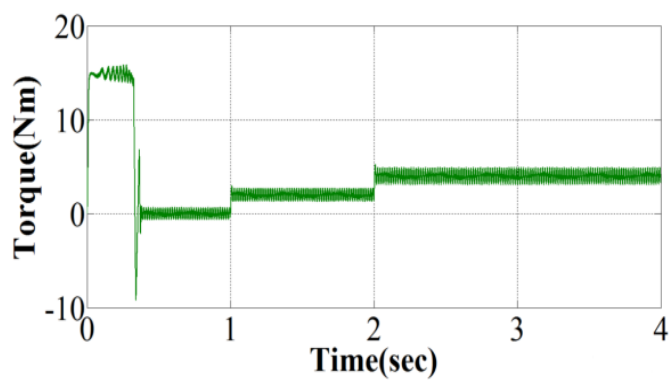

Figure (5): Electromagnetic torque response

The starting torque is higher when compared with the steady state condition, in order to overcome the motor inertia before its speed reach to the reference value. The electromagnetic torque is the same as the load torque under steady state condition, but the torque produced by the PI controller has a higher oscillation. 


\section{Case2}

In this case, both the speed and the load are constant. Simulation results are given when the motor is run under the load torque condition at rated of $3 \mathrm{Nm}$ with constant speed of $3000 \mathrm{rpm}$ as shown in figure:

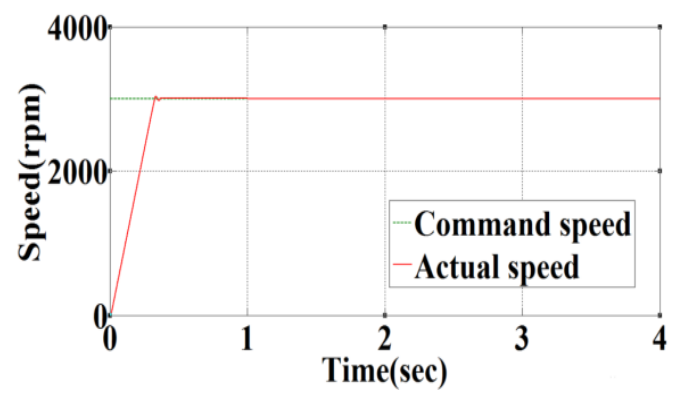

Figure (6): Speed response

Figure (7) shows the three phases current, these currents are obtained using Park's reverse transformation. . The three phase currents has a higher ripple with overshoot equal to $0.06 \%$, torque ripple is $8 \%$,rise time equal to $30 \mathrm{msec}$.

\section{Figure (7): Iabc current response}

Figure (8) shows the electromagnetic torque of the motor, it can be noticed that the torque is constant at loaded it at a constant value.

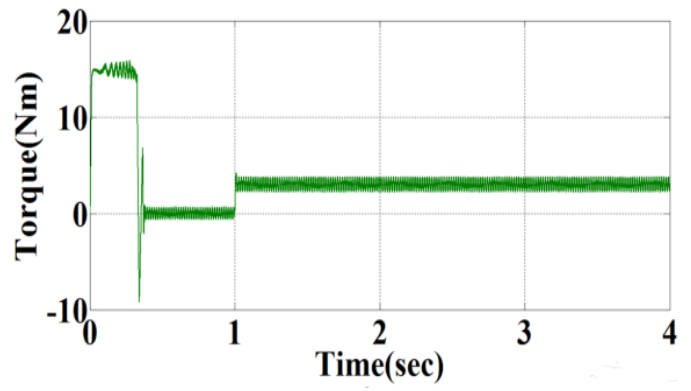

Figure (8): Electromagnetic torque response

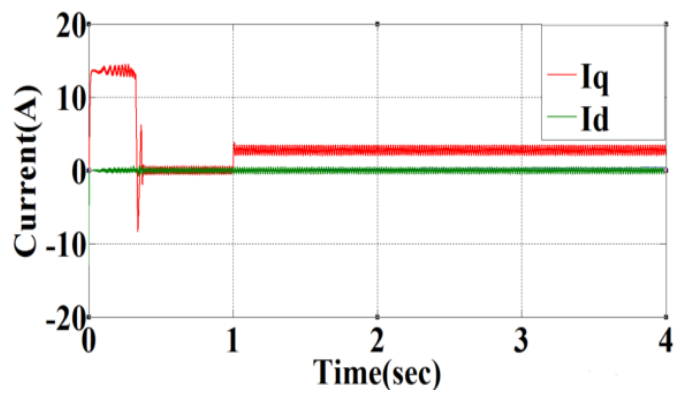

Figure (9): Iqd current response

The $\mathrm{d}$ and q component of the stator current is given in Figure (9).And it is noticing the Iqd current response as the same as before case when loads are variable.

Case 3:

In this case the speed is variable and the load constant. Simulation results are given when the load torque is $3 \mathrm{Nm}$ step as and speed is varied from 0 up to $3500 \mathrm{rpm}$ as shown in the figure with torque ripple is $7 \%$, rise time $65 \mathrm{msec}$ and overshoot $0.003 \%$ for a speed response

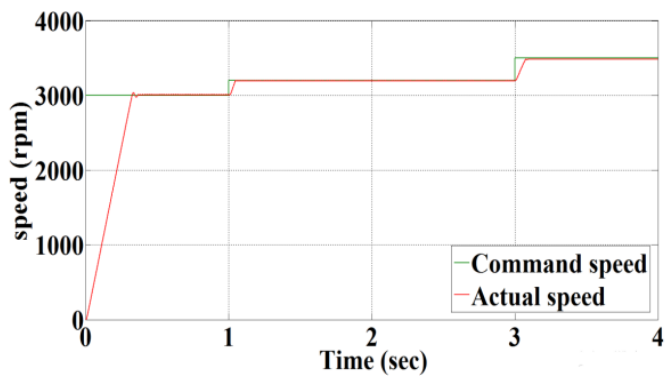

Figure (10): speed response
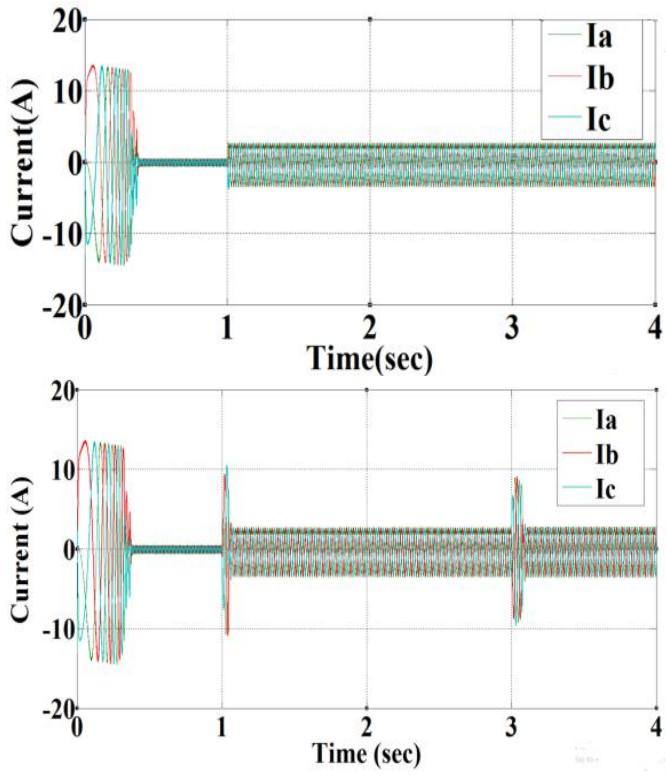

Figure (11): Iabc current response

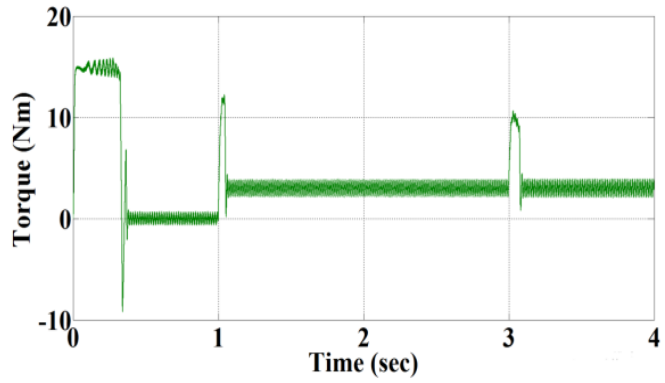

Figure (12): Electromagnetic torque response

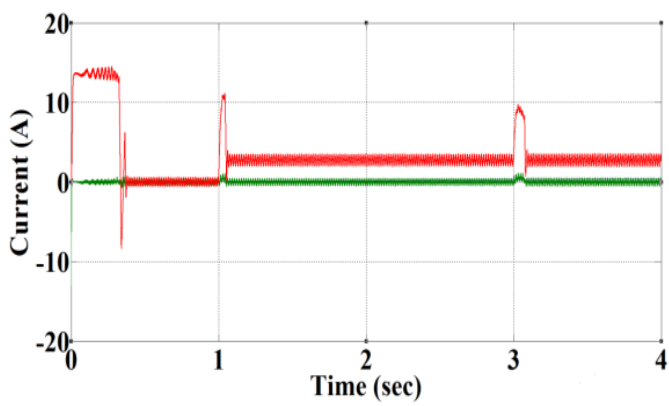

Figure (13): Iqd current response 
In case when the motor runs under the full load torque condition, then the actual speed never reach to its reference with a suitable steady state speed error. In addition, the speed response has an oscillation and overshoot in addition to the high value of electromagnetic torque ripples.
With the PI controller tuned by classical trial and error method. It is obvious from the results the reduction in the steady state error and oscillation

\subsection{Fuzzy-PI controller}

The fuzzy PI controller Simulink model is shown in Figure (14).

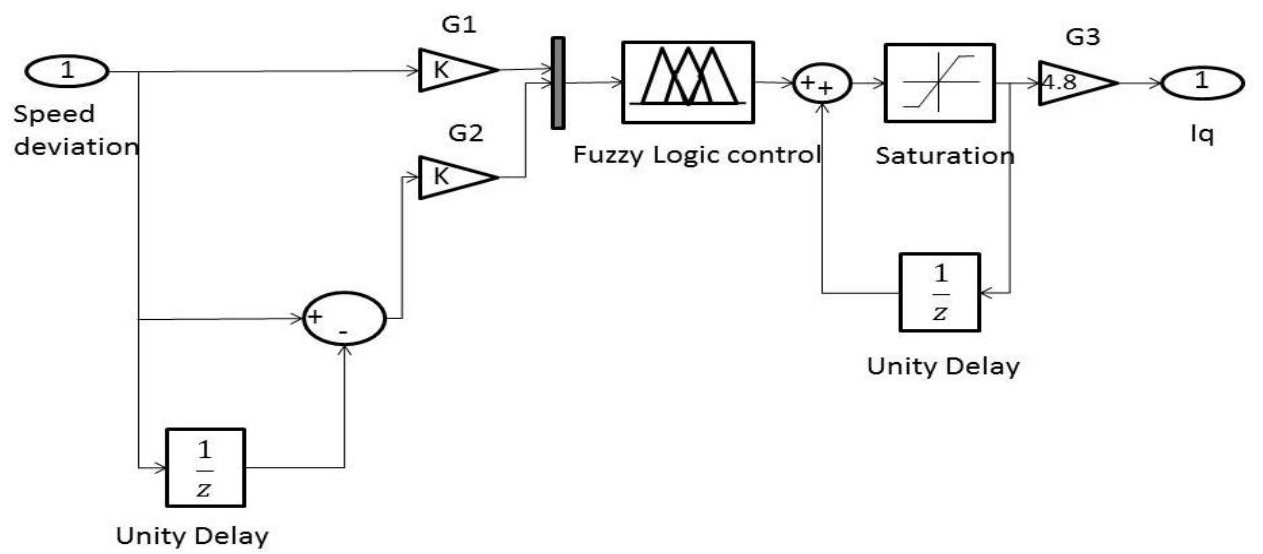

Figure (14): Simulink model of Fuzzy PI controller

Fuzzy PI-controller block consists of two inputs error and change of error with integrated output. This block provided with scaling factors (Gain) on each input and output, where the value of $\mathrm{G} 1=0.0007, \mathrm{G} 2=0.694$ and $\mathrm{G} 3=4.8$.

The base Rules for Fuzzy PI-speed controller are illustrated in Table (1.1).

\section{Table (1.1): Rules for Fuzzy PI-controller}

\begin{tabular}{|c|c|c|c|c|c|c|c|}
\hline \multicolumn{1}{|c|}{$\boldsymbol{e}$} & & & & & & & \\
\hline $\mathrm{NL}$ & $\mathrm{NL}$ & $\mathrm{NM}$ & $\mathrm{NS}$ & $\mathrm{Z}$ & $\mathrm{PS}$ & $\mathrm{PM}$ & $\mathrm{PL}$ \\
\hline $\mathrm{NM}$ & $\mathrm{NL}$ & $\mathrm{NL}$ & $\mathrm{NM}$ & $\mathrm{NM}$ & $\mathrm{NS}$ & $\mathrm{Z}$ & $\mathrm{PS}$ \\
\hline $\mathrm{NS}$ & $\mathrm{NL}$ & $\mathrm{NL}$ & $\mathrm{NS}$ & $\mathrm{NS}$ & $\mathrm{Z}$ & $\mathrm{PS}$ & $\mathrm{PM}$ \\
\hline $\mathrm{Z}$ & $\mathrm{NL}$ & $\mathrm{NM}$ & $\mathrm{NS}$ & $\mathrm{Z}$ & $\mathrm{PS}$ & $\mathrm{PM}$ & $\mathrm{PL}$ \\
\hline $\mathrm{PS}$ & $\mathrm{NM}$ & $\mathrm{NS}$ & $\mathrm{Z}$ & $\mathrm{PS}$ & $\mathrm{PS}$ & $\mathrm{PM}$ & $\mathrm{PL}$ \\
\hline $\mathrm{PM}$ & $\mathrm{NS}$ & $\mathrm{Z}$ & $\mathrm{PS}$ & $\mathrm{PM}$ & $\mathrm{PM}$ & $\mathrm{PL}$ & $\mathrm{PL}$ \\
\hline $\mathrm{PL}$ & $\mathrm{Z}$ & $\mathrm{PS}$ & $\mathrm{PM}$ & $\mathrm{PL}$ & $\mathrm{PH}$ & $\mathrm{PL}$ & $\mathrm{PL}$ \\
\hline
\end{tabular}

\section{Case 1:}

In this case the speed is constant and the load is variable.

Simulation results are given at the rated speed of $3000 \mathrm{rpm}$ and the load torque is varied from 0 up to $6.8 \mathrm{Nm}$ in step as [0-2-46.8] and it can be noticed that when load is increase the electromagnetic torque and the three phase $(a b c)$ currents response increase also with torque ripple is $5 \%$ and overshoot with $0.14 \%$ of the torque response. Figures (15) to (18) show these operating conditions.

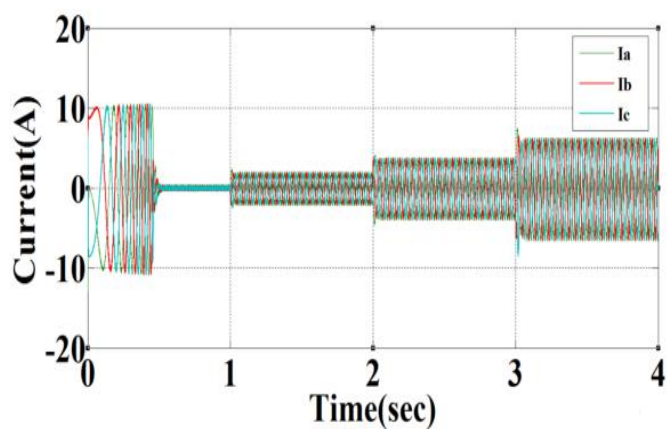

Figure (15): I abc current response

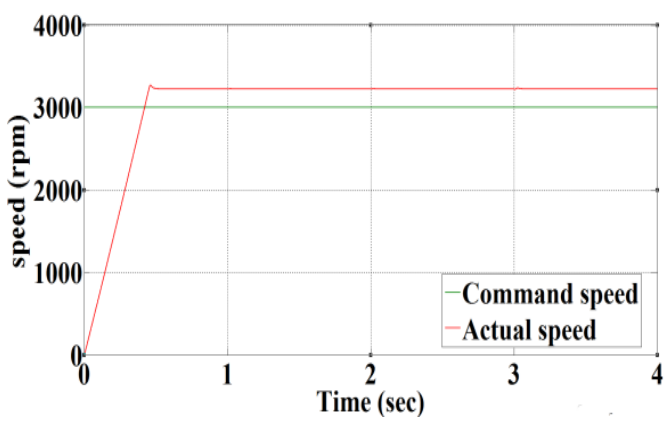

Figure (16): speed response

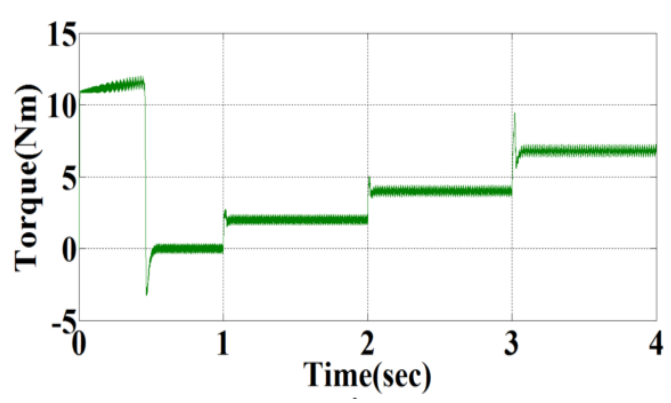

Figure(17):Electromagnetic torque 


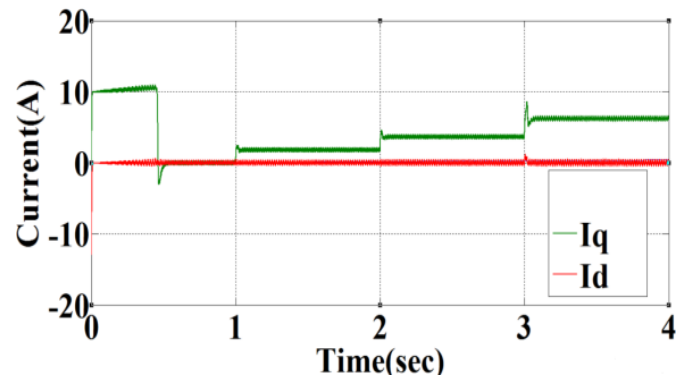

Figure (18): Iqd current response

Case 2:

In this case, both the speed and the load are constant. Simulation results are given when the motor is run under load torque conditions at rated of $3 \mathrm{Nm}$ and speed $0 \mathrm{f} 3000 \mathrm{rpm}$ and the torque ripple is measured at electromagnetic torque and finds it also 5\%. Figures (19) to (22) show these operating conditions.

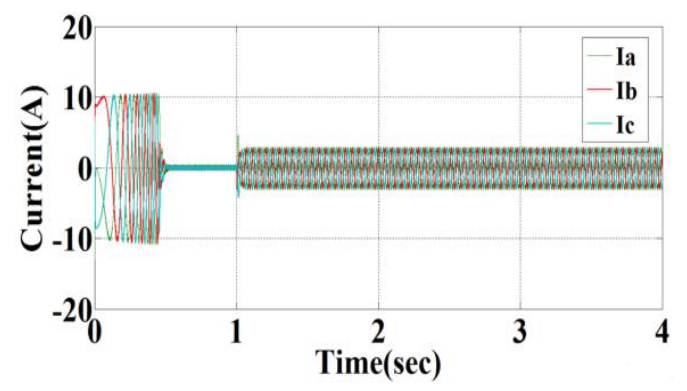

Figure(19):Iabc current response

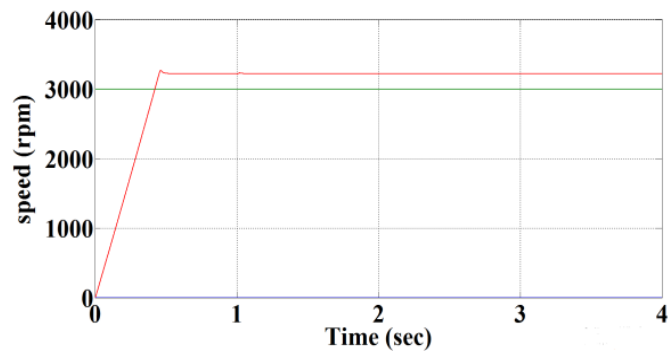

Figure (20): speed response

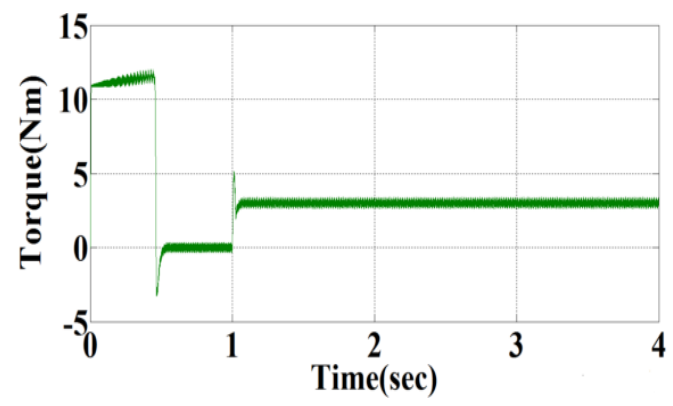

Figure (21): Electromagnetic torque

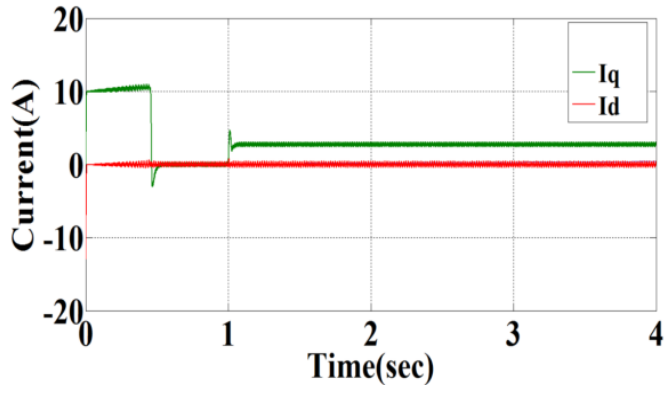

Figure (22):Iqd current response

Case 3:

In this case the speed is variable and the load is constant. Simulation results are given when the load torque is $3 \mathrm{Nm}$ in step as and speed is varied from 0 up to $3500 \mathrm{rpm}$. Figures (23) to (26) show these operating conditions.

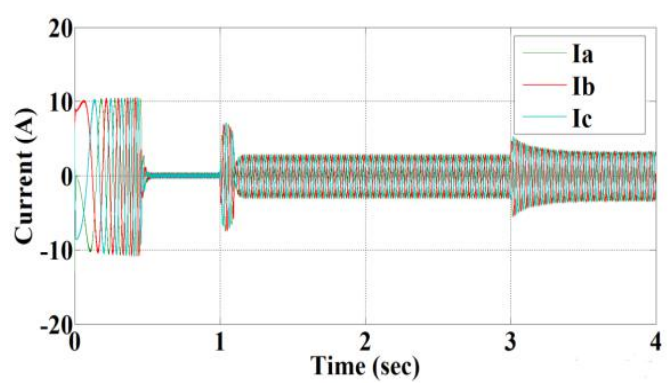

Figure (23): Iabc current response

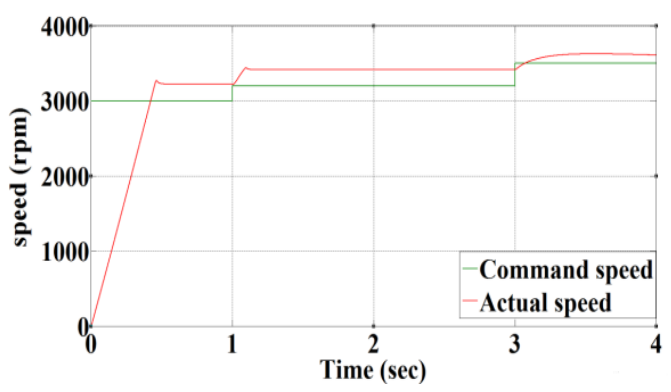

Figure(24):speed response

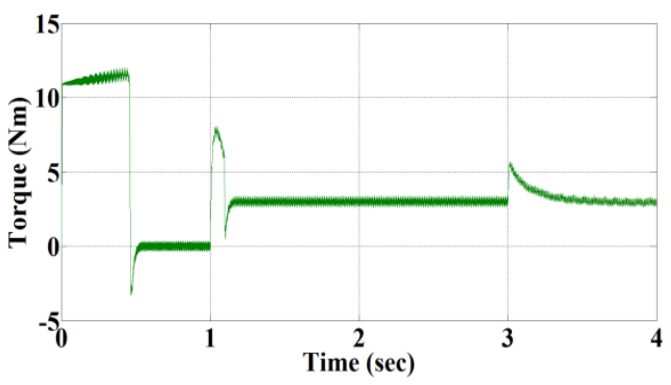

Figure (25): Electromagnetic torque 


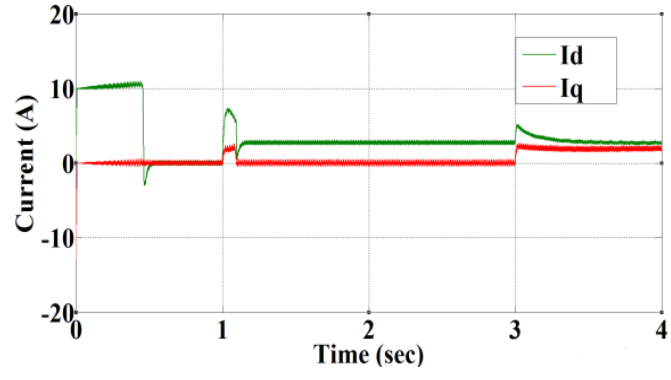

Figure(26):Iqd current response

\section{SIMULATION RESULTS,}

\section{COMPARISONS}

A comparison between different controllers for speed and torque control of the PMSM based on FOC with different load and speed conditions shown below and it can be observed that with a PI controller also reduce error but there is some steady state error and over shoot are higher than fuzzy controller.

\section{Case 1:}

Figures (27) to (29) show the three currents response, speed response and electromagnetic torque for both PI and Fuzzy control respectively.

When a variable load is applied from 0 to $6.8 \mathrm{Nm}$ in step [0 24 6.8] and constant speed with $314(\mathrm{rad} / \mathrm{sec})$ and it can be observed when the load increase the steady state error of electromagnetic torque and speed increase respectively.

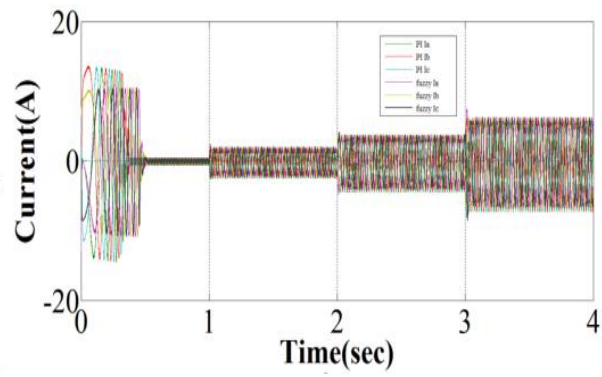

Figure (27): Iabc current response

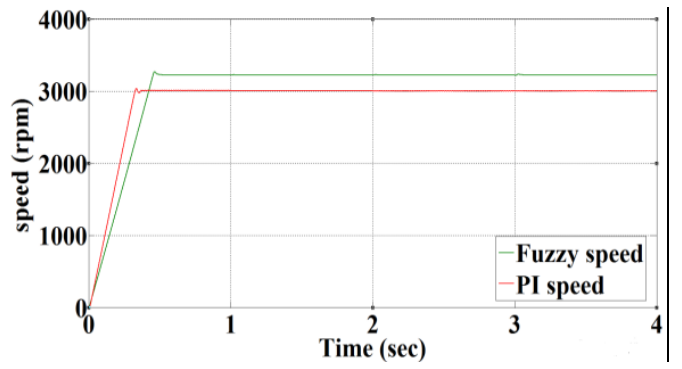

Figure (28): speed response

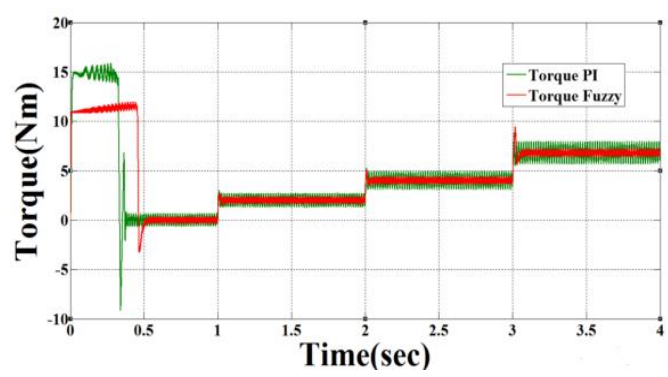

Figure(29): Electromagnetic torque
Case 2:

Figures (30) to (32) show the three current responses, speed response and electromagnetic torque for both PI and Fuzzy control respectively.

When the speed and load torque are applied to a constant values of $3 \mathrm{Nm}$ for the torque and a speed of $314(\mathrm{rad} / \mathrm{sec})$ respectively.

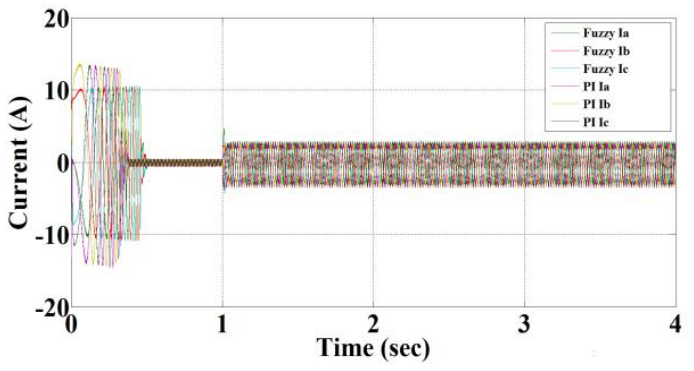

Figure(30): Iabc current response

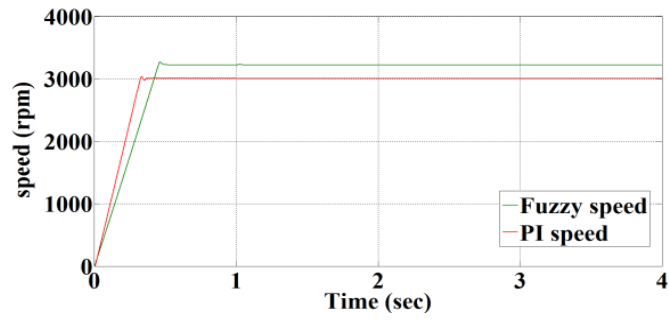

Figure (31): speed response

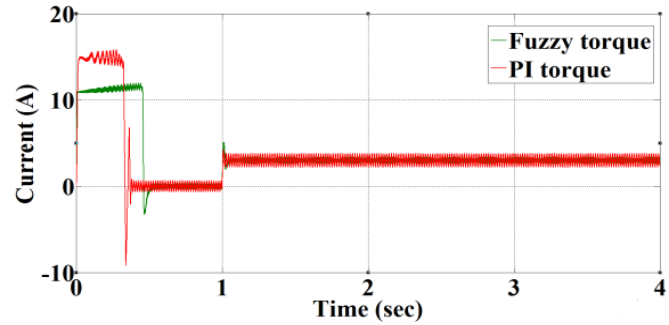

Figure (32): Electromagnetic torque

Case 3:

Figures (33) to (35) show the three current response, speed response and electromagnetic torque for both PI and Fuzzy control respectively.

When a variable speed with constant load is applied, the simulation result with speed in steps [314-334-364] rad/sec and the load is kept $3 \mathrm{Nm}$.

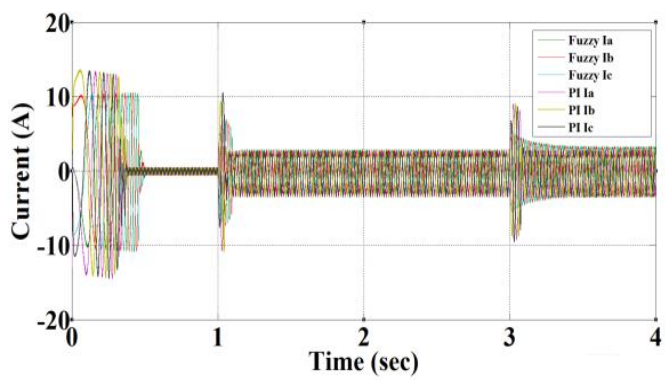

Figure(33) :Iabc current response 


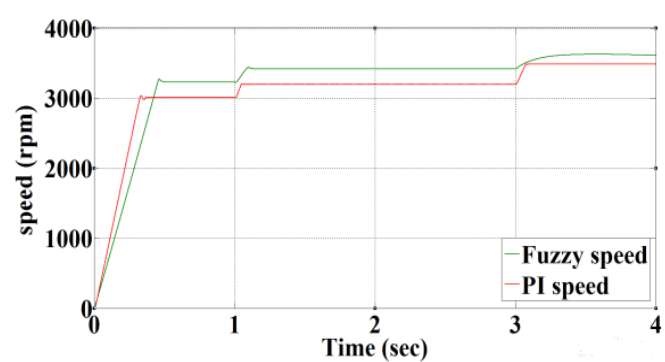

Figure (34): speed response

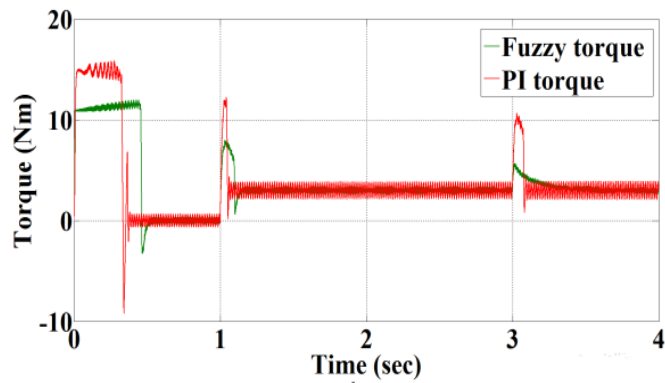

Figure (35): Electromagnetic torque

\section{NOMENCLATURES}

R-Motor phase resistance ( $\Omega$ )

$L_{d}-$ d-axis inductance $(\mathrm{H})$

$L_{q}-$ q-axis inductance $(\mathrm{H})$

P-Number of magnetic poles

$T_{e}$-Electromagnetic torque $(\mathrm{Nm})$

$T_{L_{-}}$Load torque (Nm)

B-Viscous damping coefficient (Nm.s)

$\mathrm{J}$-Moment of inertia of the motor $\left(\mathrm{Kg} / \mathrm{m}^{2}\right)$

$I_{d}-\mathrm{d}$-axis current in synchronous frame(A)

$I_{q}-\mathrm{q}$-axis current in synchronous frame (A)

$V_{d-}$ d-axis voltage in synchronous frame $(\mathrm{V})$

$V_{q}-$ q-axis voltage in synchronous frame (V)

$\omega_{r}-$ Motor electrical angular velocity $(\mathrm{rad} / \mathrm{s})$

$\omega_{e}$ - The machine angle velocity of rotor $(\mathrm{rad} / \mathrm{s})$

$\psi_{d}-$ axis flux linkage in synchronous frame $(\mathrm{Wb})$

$\psi_{q-}$ q-axis flux linkage in synchronous frame $(\mathrm{Wb})$

$\psi_{m}-\mathrm{PM}$ flux linkage in synchronous frame $(\mathrm{Wb})$.

\section{CONCLUSION}

In case of no load, all of Fuzzy-PI, and PI based on trial and error controllers have a better performance with zero steady state error and the torque remains at zero as there is no load. But, when load is applied after a specified time, the PI controller with gains tuned by trial and error method shows a steady state speed error that is proportional to applied load. In case of light load, the motor is not too affected, but in the case of higher load applied to the motor the situation is different by higher values of steady state error. The speedy response has an oscillation and overshoot in addition to the high value of electromagnetic torque ripples. In case of Fuzzy-PI controller shows an improvement in performance in terms of reducing steady state error, rising time, maximum overshoot of the speedy response with less oscillation and the electromagnetic torque ripples is reduced.

The proposed controllers can be arranged according to the performance in the simulation of this work as below:

1) PI-controller tuned by trial and error method.

2) Fuzzy PI controller.

\section{REFERENCES}

[1] R.Krishnan,"Permanent magnet synchronous and Brushless DC Motor Drive".Electrical and computer Engineering Department Virginia Tech,Blackburg, Virginia,U.S.A,book,2010.

[2] Iulian M.T. BIROU, Calin C. RUSU,Sorin Gh. PAVEL and Virgil MAIER ," Real-Time Robust Controlled Driving System with Permanent-Magnet Synchronous Motor", International Conference and Exposition on Electrical and Power Engineering , 16-18 October, Iasi, Romania,2014.

[3] Guphran Gaua Ahmed, "Comparative study on permanent Magnet Synchronous Motor Drive system, Master thesis, department of electrical Engineering,

[4] JACEK F.GIERAS, "Permanent magnet motor Technology". Hamilton sundstrand A erospace, Rockford, Illinois, U.S.A. University of technology and life Science ,Bydgoszez,poland., Book,2010.

[5] Boonyang Planglang, sittichai Kantawong and Akeratana Noppakant,"Study of Generator Mode on Permanent Magnet Synchronous Motor (PMSM)for Application on Elevator Energy Regenerative Unit (EERU), Sciverse Science Direct Energy Procedia 34 ( 2013 ) 382 389.Universitynof Technology, Iraq, July/2013.

[6] Iulian M.T. BIROU, Calin C. RUSU,Sorin Gh. PAVEL and Virgil MAIER ," Real-Time Robust Controlled Driving System with Permanent-Magnet Synchronous Motor", International Conference and Exposition on Electrical and Power Engineering , 16-18 October, Iasi, Romania, 2014.

[7] Pnuong Hue Tran, "Matlab/Simulink implementation and analysis of three pulse _width_modulation (PWM)Techniques,Boise state University,thesis, May 2012.

[8] PRAGASEN PILLAY , and Ramu Krishnan, ,"Control characteristics and speed control Design for a high performance pmsm Drive ,IEEE Transaction on power Elecronics ,VOL 5 NO 2, April,1990.

[9] Pewmaikan C.Srisertpol J.,and Khajorutraidet C."Adaptive Fuzzy Logic compensator for PMSM Torquencontrol system", International Journal of modeling and optimization, vol.2, NO.2, April 2012. 
[10] Chalempon Peumaikan,Jiraphon Srisertpol,Canyut Khajorntraidet "Torque control with adaptive Fuzzy logic compensator for PMSM", 2012 International conference on system modeling and optimization. IPCSIT vol. 23 2012.

[11] DavendraYadav,SunilBansal,Munendra umar1Scholar, M. Tech GBTU, Lucknow " Design, Development \& Simulation of Fuzzy Logic Controller to Control the Speed of Permanent Magnet Synchronous Motor Drive System" , International Journal of Scientific Research Engineering \& Technology, 2012.

[12] R.Rajendran and N.Devarajan, "Analysis and FPGA Realization of a Pulse Width Modulator based on Voltage Space Vectors", International Journal of Computer Application,Vol.2, No.6, June 2010

\section{APPENDIX}

The following parameter is used in the PI controller and FuzzyPI controller with speed and current loop and for inverter the DC-voltage is 540 volt

Table 1: PI controller parameters

\begin{tabular}{|c|c|c|c|}
\hline \multicolumn{3}{|c|}{ PI controller } \\
\hline \multicolumn{2}{|c|}{ Type } & $\mathrm{K}_{\mathrm{I}}$ & $\mathrm{K}_{\mathrm{P}}$ \\
\hline \multirow{2}{*}{ Current loop } & $I_{d}$ & 100 & 250 \\
\cline { 2 - 4 } & $I_{q}$ & 10.72 & 50 \\
\hline \multicolumn{2}{|c|}{ Speed Loop } & 0.01 & 6.98 \\
\hline
\end{tabular}

Table II: Fuzzy controller parameters

\begin{tabular}{|c|c|c|c|c|}
\hline \multicolumn{4}{|c|}{ Fuzzy controller } \\
\hline \multicolumn{2}{|c|}{ Type } & $\mathrm{K}_{\mathrm{I}}$ & \multicolumn{2}{|c|}{$\mathrm{K}_{\mathrm{P}}$} \\
\hline \multirow{2}{*}{$\begin{array}{c}\text { Current } \\
\text { loop }\end{array}$} & $I_{d}$ & 3.039 & \multicolumn{2}{|c|}{180.113} \\
\cline { 2 - 5 } & $I_{q}$ & 50 & \multicolumn{2}{|c|}{250} \\
\hline \multirow{2}{*}{ Speed Loop } & $\mathrm{G} 1$ & $\mathrm{G} 2$ & $\mathrm{G} 3$ \\
\cline { 2 - 5 } & 0.0007 & 0.694 & 4.8 \\
\hline
\end{tabular}

Table III: Fuzzy controller parameters

\begin{tabular}{|c|c|}
\hline Rated Power ( $\left.\mathrm{P}_{\text {out }}\right)$ & $2.14 \mathrm{~kW}$ \\
\hline Rated voltage V(L-L) & $440.9 \mathrm{~V}$ \\
\hline Rated Speed (N) & $3000 \mathrm{rpm}$ \\
\hline Rated Current (I) & $4.4 \mathrm{~A}$ \\
\hline Rated Torque (T) & $6.8 \mathrm{Nm}$ \\
\hline Number of pole pairs (P) & 4 \\
\hline Stator resistance $\left(\mathrm{R}_{\mathrm{s}}\right)$ & $1.04 \Omega$ \\
\hline Stator inductance $\left(\mathrm{L}_{\mathrm{d}}\right.$ and $\left.\mathrm{L}_{\mathrm{d}}\right)$ & $14 \mathrm{mH}$ \\
\hline Permanent Magnet Flux $(\Psi)$ & $0.1821 \mathrm{~Wb}$ \\
\hline Moment of Inertia $(\mathrm{J})$ & $15 \mathrm{e}^{-4} \mathrm{Kgm}^{2}$ \\
\hline
\end{tabular}

